\title{
A GENERAL STRUCTURAL EQUATION MODEL WITH DICHOTOMOUS, ORDERED CATEGORICAL, AND CONTINUOUS LATENT VARIABLE INDICATORS
}

\author{
BENGT MuthÉN \\ GRADUATE SCHOOL OF EDUCATION \\ UNIVERSITY OF CALIFORNIA \\ LOS ANGELES, CALIFORNIA
}

\begin{abstract}
A structural equation model is proposed with a generalized measurement part, allowing for dichotomous and ordered categorical variables (indicators) in addition to continuous ones. A computationally feasible three-stage estimator is proposed for any combination of observed variable types. This approach provides large-sample chi-square tests of fit and standard errors of estimates for situations not previously covered. Two multiple-indicator modeling examples are given. One is a simultaneous analysis of two groups with a structural equation model underlying skewed Likert variables. The second is a longitudinal model with a structural model for multivariate probit regressions.
\end{abstract}

Key words: polychoric correlations, probit regressions, generalized least-squares, weight matrix.

\section{Introduction}

This article considers the specification and estimation of multiple-group (population) structural equation models with latent variables having multiple indicators, not all of which are continuous. A linear structure for continuous latent variables will be considered. However, in the measurement part dichotomous and ordered polytomous observed variables (indicators) will be allowed in addition to continuous indicators. Such categorical indicators are frequent in many types of applications, and it seems important to provide the powerful structural equation modeling tool also for these cases.

The methodology to be presented unifies and generalizes several lines of psychometric, econometric and biometric work. For an overview, see Muthén (1983). In particular, the paper extends the Muthen-Christoffersson methodology for factor analysis of dichotomous variables (see e.g. Muthén, 1978; Muthén and Christoffersson, 1981) to handle ordered categorical and continuous indicators and general multiple-group structural equation models with estimation of latent variable means. Hence, the paper also generalizes the Jöreskog-Sörbom ("LISREL") methodology for structural equation models (see e.g., Jöreskog, 1973, 1977; Sörbom, 1982) to handle properly categorical indicators in addition to continuous ones. New results also include a general estimation approach for all cases of the model. A three-stage, limited information, generalized least-squares (GLS) estimator is proposed, which gives large-sample chi-square tests of model fit and largesample standard errors of estimates. Some examples of analyses that the new techniques make possible are GLS factor analysis with (mixtures of continuous and) ordered polytomous indicators, testing hypotheses of both correlation and level ("mean") structures in multiple-group structural equation models, and multivariate structural regression with ordered categorical response variables (such as multivariate probit regression). In the

This research was supported by Grant No. 81-1J-CX-0015 from the National Institute of Justice, by Grant No. DA 01070 from the U.S. Public Health Service, and by Grant No. SES-8312583 from the National Science Foundation. I thank Julie Honig for drawing the figures. Requests for reprints should be sent to Bengt Muthén, Graduate School of Education, University of California, Los Angeles, California 90024. 
latter case, the new estimator provides a computationally feasible alternative to the maximum-likelihood estimator of Muthén (1979).

\section{The General Model}

Consider the following model for $G$ groups (populations) of observation units. For each group $g$ a random variable vector $y^{(g)}(p \times 1)$ is observed, which may consist of both dependent and independent variables (in a structural equation modeling sense), and both ordered categorical and continuous variables. Let $y^{*(g)}(p \times 1)$ be a vector of continuous latent response variables, one for each $y^{(g)}$ variable. Also, let $\eta^{(g)}(m \times 1)$ be a vector of continuous latent variable constructs and let $x^{(g)}(q \times 1)$ be a vector of observed independent variables for which no model structure is imposed. Observations from different groups $g$ are assumed to be independent. In what follows, the super-script $g$ should be attached to each array of the model, but will be deleted for simplicity in cases where no confusion can arise.

For each group, the model is as follows. For an ordered polytomous $y_{i}$ with $C_{i}$ categories (including the dichotomous case),

$$
y_{i}= \begin{cases}C_{i}-1, & \text { if } \tau_{i, c_{i}-1}<y_{i}^{*} \\ C_{i}-2, & \text { if } \tau_{i, c_{i}-2}<y_{i}^{*} \leq \tau_{i, c_{i}-1} \\ \vdots & \\ 1, & \text { if } \tau_{i, 1}<y_{i}^{*} \leq \tau_{i, 2} \\ 0, & \text { if } y_{i}^{*} \leq \tau_{i, 1}\end{cases}
$$

For a continuous $y_{i}$ the latent response variable is directly observed,

$$
y_{i}=y_{i}^{*} \text {. }
$$

As in conventional structural equation modeling, assume a linear measurement structure,

$$
y^{*}=v+\Lambda \eta+\varepsilon
$$

and the linear structural equation system

$$
\eta=\alpha+B \eta+\Gamma x+\zeta
$$

where $B$ has zero diagonal elements and $I-B$ is non-singular.

For each group, multivariate normality will be specified for the distribution of $y^{*}$ conditional on $x$. It is useful to distinguish between two cases of the general model. In Case A we have $q=0$, so that the conditioning on $x$ is vacuous. In Case B we have $q>0$. Case $B$ is relevant when there is a set of observed independent variables $x$ for which no model structure is imposed, so that a distributional specification (such as normality) for $x$ is unnecessary. This includes situations with multivariate regression and simultaneous equation modeling, where $x$ 's can be dummy coded and/or non-stochastic. The distinction between Case A and Case B is also important to the estimation procedure proposed in Section 3, when $y$ contains one or more categorical variables.

Due to the normality specification, it suffices to consider first- and second-order moments for the latent response variables. With conventional assumptions,

$$
\begin{aligned}
& E\left(y^{*} \mid x\right)=v+\Lambda(I-B)^{-1} \alpha+\Lambda(I-B)^{-1} \Gamma x, \\
& V\left(y^{*} \mid x\right)=\Lambda(I-B)^{-1} \Psi(I-B)^{-1} \Lambda^{\prime}+\Theta,
\end{aligned}
$$

where for Case $\mathrm{A}(q=0)$ the conditioning on $x$ is without effect, so that the last term of 
(5) vanishes. With categorical $y$ variables, the scale of the latent response variables $y^{*}$ is indeterminate and we may consider standardized $y^{*}$, such that instead of the left sides of (5) and (6), we have

$$
\begin{gathered}
\Delta E\left(y^{*} \mid x\right), \\
\Delta V\left(y^{*} \mid x\right) \Delta,
\end{gathered}
$$

where $\Delta$ is a diagonal matrix of scaling factors,

$$
\operatorname{diag}(\Delta)=\left[\operatorname{diag}\left(V\left(y^{*} \mid x\right)\right)\right]^{-1 / 2}
$$

In a single group (population) with categorical variables we usually standardize to $\Delta=I$.

With categorical $y$ variables, the distribution of the observed variables is deduced by integrating over the corresponding latent response variables $y^{*}$ (c.f., Muthén, 1979; Muthén and Christoffersson, 1981). The integration limits involve the expression [c.f. Eq. $(1),(11)]$

$$
\delta_{i}\left[\tau_{i, c}-\left[E\left(y^{*} \mid x\right)\right]_{i}\right]
$$

where $\delta_{i}$ is the $i$ th diagonal element of $\Delta, c=0,1, \ldots, C_{i}-1$, and $\left[E\left(y^{*} \mid x\right)\right]_{i}$ is the $i$ th row of $(5)$.

\section{The General Estimation Procedure}

This article proposes an estimation approach for the general model, which uses weighted least squares with limited, first and second order sample information. The estimation approach consists of three stages. In the first stage, first order statistics will be consistently estimated by maximum-likelihood (ML). In the second stage, second order statistics will be consistently estimated by conditional ML for given first stage estimates. The details of these first two stages will vary depending on the type of indicators involved and whether Case A or Case B is considered. In the third stage, which is common to all situations, the model parameters will be consistently estimated, using the first and second order statistics generated by the previous stages.

\subsection{The General Model Structure}

It is convenient to summarize the structure of the general model from (5), (6), (7), and (8) in three parts, covering both Case A and Case B. Deleting the group index, consider the vectors $\sigma_{1}, \sigma_{2}, \sigma_{3}$,

$$
\text { part 1: } \sigma_{1}=\Delta^{*}\left\{K_{\tau} \tau-K_{v}\left[v+\Lambda(I-B)^{-1} \alpha\right]\right\},
$$

(mean/threshold/reduced-form regression intercept structure)

part 2: $\sigma_{2}=\operatorname{vec}\left\{\Delta \Lambda(I-B)^{-1} \Gamma\right\}$,

(reduced-form regression slope structure)

$$
\text { part 3: } \sigma_{3}=K \text { vec }\left\{\Delta\left[\Lambda(I-B)^{-1} \Psi(I-B)^{\prime-1} \Lambda^{\prime}+\Theta\right] \Delta\right\} \text {. }
$$

(covariance/correlation/reduced-form residual correlation structure)

Here $\Delta$ is a diagonal matrix of scaling factors useful in multiple-group analyses with categorical variables. $\Delta^{*}$ contains the same element as $\Delta$ but diagonal elements are duplicated for categorical variables with more than one threshold (more than two categories), $K_{\tau}$ and $K_{v}$ similarly distribute elements from the vectors they pre-multiply, where $K_{\tau}$ has a row of zeros for each continuous variable, the vec operator strings out matrix elements row-wise into a column vector, and $K$ selects lower-triangular elements from the vector of 
symmetric matrix elements it pre-multiplies, where diagonal elements are only included if the corresponding observed variable is continuous.

Variable $y_{i}$ contributes $C_{i}-1$ elements to $\sigma_{1}$ if it is categorical with $C_{i}$ categories, and a single element (the mean) if it is continuous. Variable $y_{i}$ contributes $q$ elements to $\sigma_{2}$. The pair of variables $y_{i}$ and $y_{j}$ contribute a single element to $\sigma_{3}$ if both variables are categorical (a correlation), and may contribute one more element for each $y$ that is continuous (a variance). Any model fitting into this general framework is identified if and only if its parameters are identified in terms of $\sigma_{1}, \sigma_{2}, \sigma_{3}$.

The model of (11), (12), and (13) utilizes the common structure of Case A and Case B. Case A considers means and covariances/correlations of $y^{*}$; see (5), (6), and (7), (8). For Case A, part 1 and part 3 would normally be used. Part 2 is not needed. Part 3 corresponds to the covariance/correlation structure, while part 1 would also be used when a structure on the levels of the latent variables is desired such as in a multiple-group analysis with estimation of latent variable means. Case A with part 1 and part 3 covers all Jöreskog-Sörbom (LISREL) models. Case B considers reduced-form regression structures for the regression of $y^{*}$ on $x$; see (5), (6), and (7), (8). Part 1 contains the intercept structure (the first two terms of (5) and (7)), part 2 contains the regression slope structure (the last term of (5) and (7)), while part 3 contains the residual covariance/correlation structure ((6) and (8)).

\subsection{The First and Second Estimation Stages}

The elements of $\sigma_{1}, \sigma_{2}$, and $\sigma_{3}$ for each group may be consistently estimated by ML as $s_{1}, s_{2}$, and $s_{3}$ in estimation stages one and two. Consider a random sample of size $N$ for a certain group (population). We observe $y$ in Case A, and $y$ and $x$ in Case B. Note again that conditioning on $x$ will be ignored below for Case A $(q=0)$. Let $F_{i}(i=1,2, \ldots, p)$ denote the univariate $\log$ likelihood function for $y_{i}$ given all $x$ 's and $F_{i j}(i=1,2, \ldots, p$; $j=1,2, \ldots, p ; j<i)$ the bivariate $\log$ likelihood function for $y_{i}$ and $y_{j}$ given all $x$ 's and given the estimates from maximization of the $F_{i}$ 's. Maximizing $F_{i}$ 's gives limited information ML estimates of the $\sigma_{1}$ and the $\sigma_{2}$ (Case B only) elements, while maximizing the $F_{i j}$ 's give limited information conditional ML estimates of the $\sigma_{3}$ elements, given estimates of $\sigma_{1}$ and $\sigma_{2}$ elements. For simplicity in the description below, we will only consider the case where from maximization of $F_{i j}$ a single correlation is estimated (although when one or both of the $y$ 's is (are) continuous, estimates of covariances and variances may result).

Let $\sigma_{1 i}$ and $\sigma_{2 i}$ denote the vectors of elements contributed by variable $y_{i}$, and $\sigma_{3 i j}$ the single element contributed by the pair of variables $y_{i}, y_{j}$. Consider the vector of firstorder derivatives,

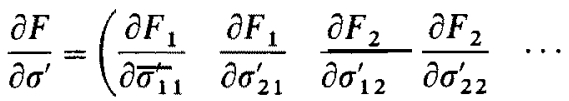

$$
\begin{aligned}
& \left.\frac{\partial F_{p}}{\partial \sigma_{1 p}^{\prime}} \frac{\partial F_{p}}{\partial \overline{\sigma_{2 p}^{\prime}}} \frac{\partial F_{21}}{\partial \sigma_{321}} \frac{\partial F_{31}}{\partial \sigma_{331}} \cdots \frac{\partial F_{p p-1}}{\partial \sigma_{3 p p-1}}\right) .
\end{aligned}
$$

The first two stages of the proposed estimator are defined as:

$$
\partial F / \partial \sigma=0 .
$$

The computations of (15) are straightforward for all combinations of $y$ indicators; see Muthén (1983) and references therein. For instance, consider the example of $p$ dichotomous $y$ indicators. In Case A, the first stage gives the $p$ estimates of $\sigma_{1}$ (the sample thresholds) and the second stage produces estimates of the $p(p-1) / 2$ tetrachoric correlations, the elements of $\sigma_{3}$ (see e.g. Muthén, 1978). Similarly, for Case B, $p$ stage one 
univariate probit regressions of each $y_{i}$ on $q$ x's give the $p$ estimates of $\sigma_{1}$ (the reducedform regression intercepts) and the $p \times q$ estimates of $\sigma_{2}$ (the reduced-form slopes), whereas the second stage produces estimates of the $p(p-1) / 2$ reduced-form residual correlations of $\sigma_{3}$ (see e.g. Muthén, 1979).

A consistent estimator of the asymptotic covariance matrix of the estimates $\hat{\sigma}$ obtained from (15) is given by the following large-sample approximations. Consider the asymptotic expansion

$$
\frac{\partial F}{\partial \sigma}+\frac{\partial^{2} F}{\partial \sigma \partial \sigma^{\prime}}(\hat{\sigma}-\sigma) \approx 0
$$

and let $\partial F / \partial \sigma$ be rewritten as

$$
\partial F / \partial \sigma=\sum_{r=1}^{N} \partial F(r) / \partial \sigma
$$

where $r$ runs over the observation units in the particular sample of size $N$ that is considered (with multiple groups, the groups are considered separately). With the partitioning

$$
\partial^{2} F / \partial \sigma \partial \sigma^{\prime}=\left[\begin{array}{ll}
A_{11} & A_{12} \\
A_{21} & A_{22}
\end{array}\right]
$$

$A_{11}$ is a block diagonal matrix involving the singly subscripted $F$ 's and $A_{22}$ is a diagonal matrix with rows corresponding to the doubly subscripted $F$ 's. Note that $A_{12}=0$. In large samples, we may use the following common approximations to the probability limit of (18). Each matrix on the diagonal of $A_{11}$ may be approximated as

$$
\sum_{r=1}^{N}\left[\begin{array}{l}
\partial F_{i}(r) / \partial \sigma_{1 i} \\
\partial F_{i}(r) / \partial \sigma_{2 i}
\end{array}\right]\left[\begin{array}{ll}
\partial F_{i}(r) / \partial \sigma_{1 i}^{\prime} & \left.\partial F_{i}(r) / \partial \sigma_{2 i}^{\prime}\right]
\end{array}\right.
$$

the non-zero elements of $A_{21}$ can be approximated as ( $s=i$ or $j$ )

$$
\sum_{r=1}^{N} \partial F_{i j}(r) / \partial \sigma_{3 i j}\left[\begin{array}{ll}
\frac{\partial F_{i j}(r)}{\partial \sigma_{1 s}^{\prime}} & \frac{\partial F_{i j}(r)}{\partial \sigma_{2 s}^{\prime}}
\end{array}\right]
$$

and the diagonal elements of $A_{22}$ as

$$
\sum_{r=1}^{N}\left(\partial F_{i j}(r) / \partial \sigma_{3 i j}\right)^{2}
$$

Let $B$ denote the above approximation to the $A$ matrix of (18). It then follows that in large samples a consistent estimator of the limiting covariance matrix of $\hat{\sigma}-\sigma$ is

$$
B^{-1} \sum_{r=1}^{N} \frac{\partial F(r)}{\partial \sigma} \cdot \frac{\partial F(r)}{\partial \sigma^{\prime}} B^{-1,}
$$

calculated at $\sigma=\hat{\sigma}$.

\subsection{The Third Estimation Stage}

For group $g$, let $s^{(g)^{\prime}}=\left(s_{1}^{\left(g \gamma^{\prime}\right.} s_{2}^{(g)^{\prime}} s_{3}^{(g)^{\prime}}\right), \sigma^{(g)^{\prime}}=\left(\sigma_{1}^{(g)} \sigma_{2}^{(g)^{\prime}} \sigma_{3}^{(g)^{\prime}}\right)$. In the third and final estimation stage, the model parameters are estimated by minimization of the weighted leastsquares fitting function

$$
F_{3}=\sum_{g=1}^{G}\left(s^{(g)}-\sigma^{(g)}\right)^{\prime} W^{(g)-1}\left(s^{(g)}-\sigma^{(g)}\right)
$$

where the superscript $g$ denotes the $g$ th group and $W^{(g)}$ is a positive definite weight matrix. When the $W^{(g)}$ 's are formed as in (22), a limited-information generalized least 
squares (GLS) estimator is obtained, with asymptotically normally distributed estimates, and with $F_{3}$ calculated at the minimum providing a large-sample chi-square test of model fit to the $s^{(g)}$ 's (see e.g. Browne, 1974). Let $\theta$ be the vector of free and distinct model parameters. A consistent estimator of the asymptotic covariance matrix of the estimator $\hat{\theta}$ is obtained as

$$
\left[\sum_{g=1}^{G} A^{(g)^{\prime}} W^{(g)-1} A^{(g)}\right]^{-1},
$$

where

$$
A^{(g)}=\left[\partial \sigma^{(g)} / \partial \theta\right]_{\theta=\hat{\theta}} .
$$

The computations of the three-stage estimator for the examples below have been carried out by a general computer program LACCI (Latent Variable Analysis with Dichotomous, ordered Categorical, and Continuous Indicators), which is being developed by the author. The optimizations are carried out by the Fletcher and Powell method as modified by Gruvaeus and Jöreskog (1970, Note 1), using only first-order derivatives and allowing constraints on the parameters in the form of equalities or fixed values.

\subsection{The Three-Stage Estimator in Some Special Cases}

First, consider the situation of all $y$ 's being dichotomous. For factor analysis models, this case has been studied by Muthén (1978) and Muthén and Christoffersson (1981). The GLS weight matrix proposed here is different from theirs in that it does not build on the asymptotic covariance matrix of proportions, but rather on theory for ML estimators. However, for the classic LSAT6 and LSAT7 data sets analyzed in Muthén (1978) almost identical results emerge. The proposed formation of the GLS weight matrix is more general in that it can also handle the inclusion of $x$ variables for Case B models. Furthermore, the last estimation stage allows for general structural equation models.

Second, consider situations with $y$ 's being ordered categorical or continuous. Here, polychoric, polyserial, and ordinary Pearson product-moment correlations may be analyzed in Case A. The first two estimation stages estimate polychoric and polyserial correlations in the same way as discussed in Olsson (1979a) and Olsson et al. (1982). Such estimates are now also available in the LISREL computer program (Jöreskog and Sörbom, Note 2). However, until now correct chi-square model tests of fit or standard errors of estimates have not been available with such correlations. Olsson (1979a) presented the asymptotic variance of a polychoric correlation estimated as in our first two stages. His work is extended here in that the proposed GLS weight matrix also gives covariances among polychoric correlations (needed to obtain chi-square tests and standard errors of estimates). Our general approach to weight matrix formation also applies to the other kinds of correlations, the inclusion of part 1 statistics, and the inclusion of $x$ variables.

\section{Examples}

In this section we will consider two applications of the general methodology. With the first data set we illustrate Case A with ordered categorical variables, using both singlegroup analyses and simultaneous multiple-group analyses. With the second data set we illustrate Case B with dichotomous indicators in a longitudinal model.

\subsection{Structural Equation Modeling With Ordinal Likert Scales}

The first data set is concerned with attitudes toward blood donations among donors. These data were collected as part of a UCLA Management Field study by R. Hoston, R. Johnson, J. Rose and J. Trask under the auspices of S. Hoberman, American Red Cross 
Blood Services, Los Angeles-Orange Counties Region. L. Cooper and I. Currim, faculty supervisors of that project, provided these data for the current research. For this illustration we consider a sub-set of the data consisting of 662 individuals of age less than 35 , further divided into 354 females and 308 males. Preliminary analyses suggested a certain interpretable factor structure among a large set of attitude variables. In our illustration,

\section{TABLE. 1}

A Structural Equation Mode1: Item Wording and Univariate Statistics ${ }^{a}$

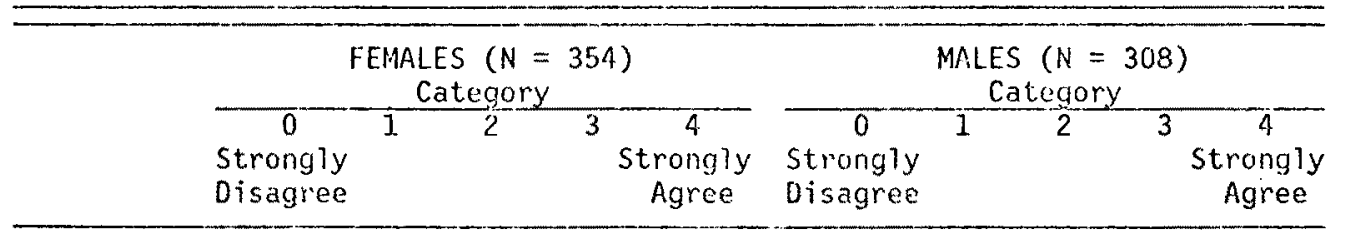

$y_{1}$ : I plan to keep giving blood at least once a year.

\begin{tabular}{|c|c|c|c|c|c|}
\hline $\begin{array}{l}\text { Frequency: } \\
\text { Percentage: } \\
\text { S/K/4: }\end{array}$ & $\begin{array}{l}16 \\
4.5\end{array}$ & $\begin{array}{llc}17, & 26 & 61 \\
4.8, & 7.3 & 17.2 \\
-1.486 / .893 / .800 \\
(-1.780 / 2.223 / 3.2\end{array}$ & $\begin{array}{l}234 \\
66.1 \\
47)\end{array}$ & $\begin{array}{l}12 \\
3.9\end{array}$ & $\begin{array}{lccc}13, & 28 & 75 & 180 \\
4.2, & 9.1 & 24.4 & 58.4 \\
-1.283 / .547 / .430 & \\
(-1.650 / 2.019 / 2.475)\end{array}$ \\
\hline
\end{tabular}

$y_{2}$ : I am willing to give blood again.

$\begin{array}{llllll}\text { Frequency: } & 8 & 6 & 11, & 37 & 292\end{array}$

Percentage: $\quad 2.3 \quad 1.7 \quad 3.1,10.5 \quad 82.5$

S/K/4:

$$
\begin{aligned}
& -2.208 / 3.576 / .384 \\
& (-3.118 / 9.787 / 4.113)
\end{aligned}
$$

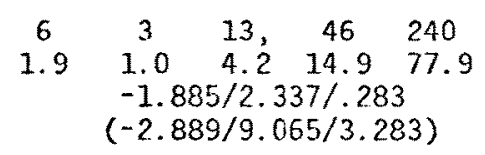

$y_{3}$ : Giving blood sometimes makes me feel weak.

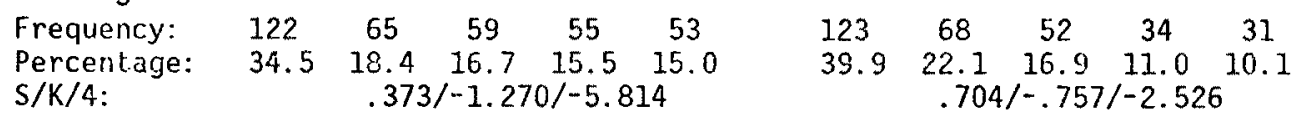

$y_{4}:$ It hurt some.

$\begin{array}{lccccc}\text { Frequency: } & 42 & 67 & 112 & 95 & 38 \\ \text { Percentage: } & 11.9 & 18.9 & 31.6 & 26.8 & 10.7\end{array}$

$\mathrm{S} / \mathrm{K} / \mathrm{4}: \quad-.149 /-.778 /-1.437$

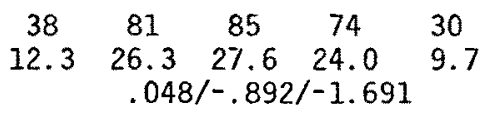

$y_{5}$ : The nurses are friendly.

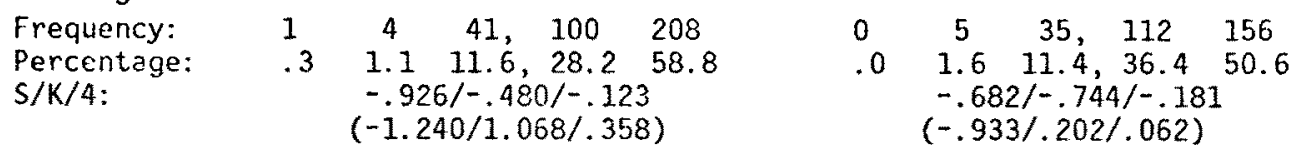

$y_{6}$ : The equipment and facilities are good.

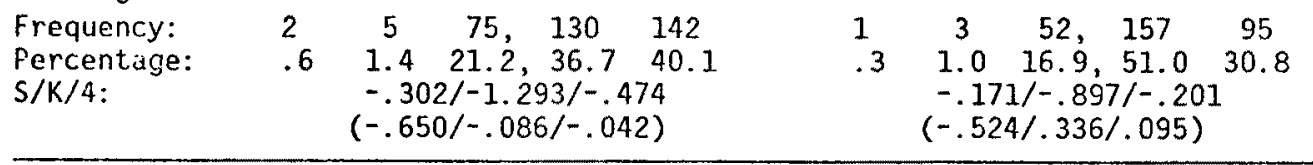

$a_{A}$ comma is used to denote the collapsing of categories to the left of it. $S / K / 4$ stands for Skewness/Kurtosis/4th order cumulant for the collapsed continuous variable scored $0,1,2,$. . In parentheses are given the values for the variable before collapsing. 
we have for simplicity chosen two indicators of each of three important factors. All six variables are five-category Likert scales which range from Strongly Disagree to Strongly Agree. In Table 1 is given the wording of the six variables and their univariate distributions.

The first two variables are of particular importance since they indicate a propensity to want to repeat blood donations (the latent variable construct $\eta_{1}$ in Figure 1 below). We

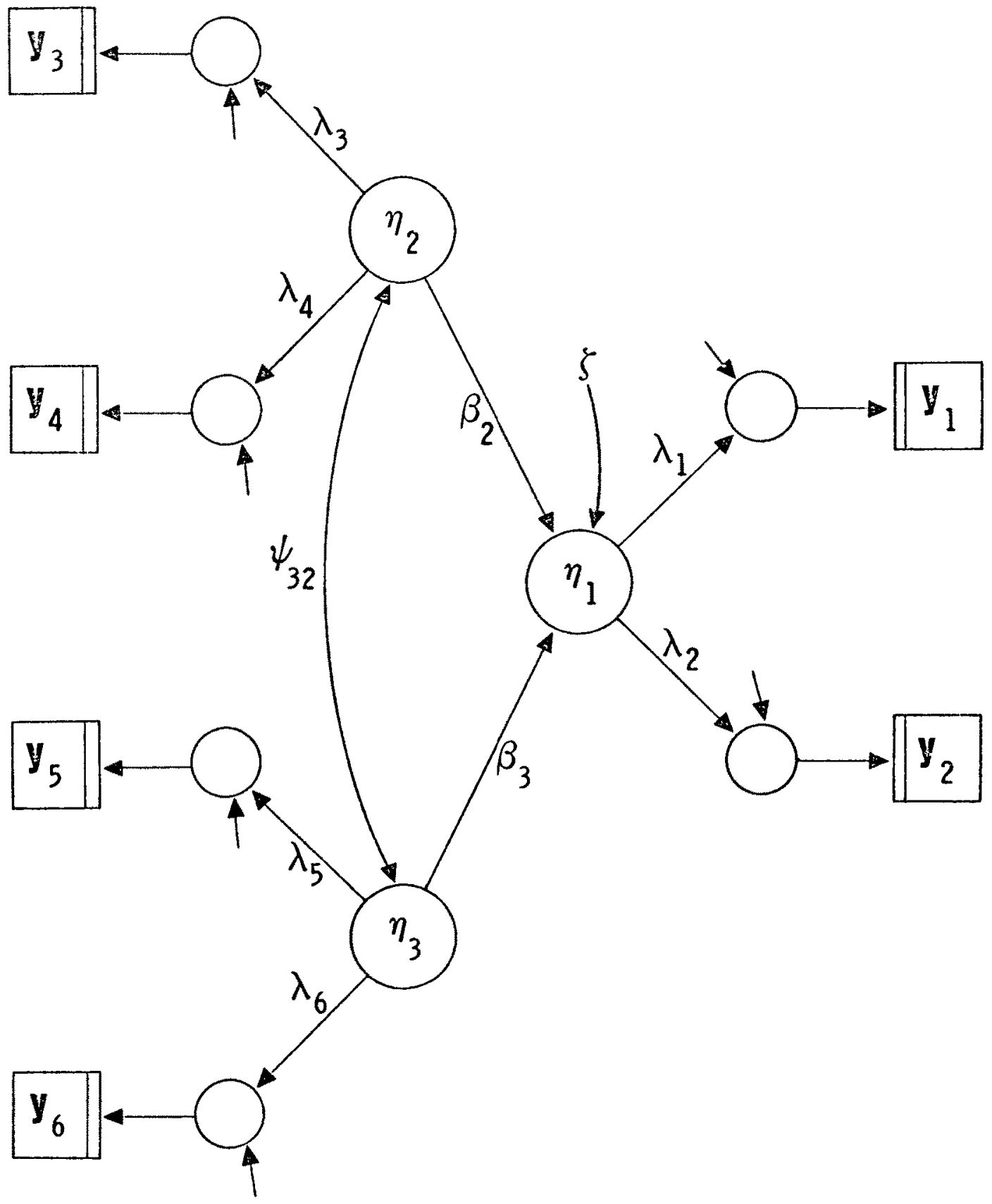

Figure 1.

A Structural Equation Model. 
may note that Females have higher sample proportions for the category Strongly Agree on both of the two dependent variables, $y_{1}$ and $y_{2}$. For Males the proportions are 0.584 $\left(y_{1}\right)$ and $0.779\left(y_{2}\right)$, while for Females they are $0.661\left(y_{1}\right)$ and $0.825\left(y_{2}\right)$. Tests for significant differences in proportions, obtain $t$-values of $0.690\left(y_{1}\right)$ and $0.956\left(y_{2}\right)$. This does not give a strong indication of sex difference in levels.

It is of interest to relate $y_{1}$ and $y_{2}$ to the other variables, which intend to measure various aspects of attitudes towards the donation experience, such as perceived physical discomfort $\left(\eta_{2}\right)$ and pleasantness of treatment $\left(\eta_{3}\right)$. The structural equation model addressing this, is given in Figure 1. It is of interest to study this model for the two sex groups separately and to compare model characteristics across the two sex groups in simultaneous, two-group analyses.

The above Likert variables are presumably not suitable for ordinary structural equation modeling, assuming continuous or continuous multivariate normal indicators (scored, say, $0,1,2, \ldots$ ). First, these Likert variables may not have equidistant scale steps and may be better viewed as ordered categorical variables than continuous ones. Second, and more importantly, the strong skewness of several of the variables (taken together with the small number of categories) will distort ordinary Pearson product moment correlations (or covariances); see e.g., Olsson (1979b).

Here, we will instead analyze polychoric correlations, applying Case $\mathbf{A}$ of the general model. In an initial step, we will assess the appropriateness of the normality specification for the latent response variables of $y^{*}$. For each pair of indicators we may use the full ML estimator, see Olsson (1979a), to estimate the polychoric correlation and the thresholds for each indicator, and obtain a large sample Pearson chi-square test of bivariate normality in each marginal two-way table. To avoid low bivariate frequencies in these tests, it was decided to collapse categories for certain variables. For $y_{1}$ the two left-most categories were combined, while for $y_{2}, y_{5}$, and $y_{6}$ the three left-most categories were combined; see Table 1. The results of these tests are given for each of the two groups and all pairs of variables in Table 2.

There seems to be no strong overall indication of misspecification, although for Males, $y_{6}$ seems to produce rather low probability values throughout. It may be noted that conservative approximations to the chi-square tests may be obtained by instead using cell frequencies as predicted from the two-stage estimator (which is not fully efficient). For these data, very similar results were observed for the two approaches.

While some sex differences are anticipated, a first analysis may test for sex invariance of $\sigma_{1}$ and $\sigma_{3}$ (not applying the structural model of Figure 1 to $\sigma_{1}$ and $\sigma_{3}$ ). This will be carried out here, providing a generalization of tests of group-invariant mean vectors and covariance matrices for normal continuous variables (see e.g. Jöreskog and Sörbom, Note 2). In what follows we will use the same collapsing of categories as was done for the tests of Table 2; see Table 1. For each group there are 17 thresholds and 15 correlations. The hypothesis of sex invariant $\sigma_{1}$ and $\sigma_{3}$ was tested in a simultaneous analysis of the two groups via the GLS estimator of (23). A chi-square value of 73.53 with 32 degrees of freedom was obtained. Allowing $\sigma_{1}$ to vary over sex, while still restricting $\sigma_{3}$ to be sex invariant, resulted in a chi-square of 19.43 with 15 degrees of freedom. Hence, there seems to be sex differences in levels $\left(\sigma_{1}\right)$, but there is no indication of sex differences in associations $\left(\sigma_{3}\right)$.

Next, we consider the structural equation model of Figure 1. First, we estimate this model for Females and Males separately. In the measurement relation (3) we standardize to $v=0$ since all $y$ 's are categorical. In the structural relation (4), $\alpha$ is a vector representing one mean for each of the two independent latent variable constructs and one intercept. In the single-group analyses we may standardize to $\alpha=0$. The matrix B con- 
TABLE 2

A Structural Equation Model: Probability Values for Pearson Chi-Square Tests of Bivariate Normality ${ }^{2}$

\begin{tabular}{|c|c|c|c|c|c|}
\hline & $y_{1}$ & $y_{2}$ & $y_{3}$ & $y_{4}$ & $y_{5}$ \\
\hline \multicolumn{6}{|c|}{ FEMALES $(N=354)$} \\
\hline$y_{2}$ & .06 & & & & \\
\hline$y_{3}$ & .98 & .07 & & & \\
\hline$y_{4}$ & .94 & .91 & .44 & & \\
\hline$y_{5}$ & .18 & .02 & .77 & .25 & \\
\hline$y_{6}$ & .15 & .28 & .19 & .31 & .05 \\
\hline \multicolumn{6}{|c|}{ MALES $(N=308)$} \\
\hline$y_{2}$ & .22 & & & & \\
\hline$y_{3}$ & .10 & .13 & & & \\
\hline$y_{4}$ & .05 & .25 & .09 & & \\
\hline$y_{5}$ & .21 & .02 & .99 & .41 & \\
\hline$y_{6}$ & .08 & .10 & .02 & .02 & .06 \\
\hline
\end{tabular}

${ }^{a}$ Entries are probability values for obtaining at least as large a chi-square value (the degrees of freedom vary between entries; see text).

tains the two slopes. In (6), $\Psi$ is a matrix containing the single residual variance and the covariance matrix for the independent latent variable constructs. Note that elements of $\Theta$ are not included as parameters to be estimated. In the single-group analyses we set $\Delta$ of (9) as the identity matrix (see also Muthén and Christoffersson, 1981, p. 410).

With the third stage GLS estimator, a chi-square test of model fit to $s_{1}$ and $s_{3}$ obtains six degrees of freedom and indicated well-fitting models for each sex; the values were 8.99 for Females and 1.49 for Males. Given these results, it is of interest to study sexinvariance of the structural equation model parameters. Since the same measurement instrument was used for both sexes, it is relevant to hypothesize sex-invariant measurement parameters $\tau$ and $\Lambda$. Sex differences will be allowed for in the structural parameters of $B$ and $\Psi$. Also, with more than one group, we can identify and estimate group differences in the vector $\alpha$, fixing $\alpha=0$ for Females. Allowing for group level differences in the latent variable constructs would seem to be necessary to account for the group differences in estimated thresholds found above. Furthermore, we will allow the measurement error variances of $\Theta$ to be different over sex, which is consistent with fixing $\Delta=I$ for Females, 
TABLE 3.1

A Structural Equation Model: Estimates for a Model of Partial Sex-Invariance. Measurement Paraneters ${ }^{a}$

\begin{tabular}{|c|c|c|c|c|c|c|c|c|}
\hline Variable & e 1 & $2^{\mathrm{Th}}$ & $\begin{array}{c}\text { hresholds } \\
3\end{array}$ & 4 & Loading & $\begin{array}{l}\text { Scale Factgr } \\
\text { for Males }\end{array}$ & $\begin{array}{r}\text { Reliab } \\
\text { Fenlales }\end{array}$ & $\begin{array}{l}\text { ility } \\
\text { Males }\end{array}$ \\
\hline$y_{1}$ & & $\begin{array}{r}-1.229 \\
(.063 \\
-19.5)\end{array}$ & $\begin{array}{l}-.944 \\
(.059 \\
-16.0)\end{array}$ & $\begin{array}{r}-.457 \\
(.048 \\
-9.5)\end{array}$ & $\begin{array}{c}1.000^{\mathrm{C}} \\
- \\
-\end{array}$ & $\begin{array}{r}1.553 \\
(.155 \\
10.0)\end{array}$ & .816 & .825 \\
\hline$y_{2}$ & & & $\begin{array}{r}-1.408 \\
(.082 \\
-17.2)\end{array}$ & $\begin{array}{l}-.91 .2 \\
(.046 \\
-19.8)\end{array}$ & $\begin{array}{r}1.092 \\
(.075 \\
14.6)\end{array}$ & $\begin{array}{l}1.436 \\
(.154 \\
9.3)\end{array}$ & .973 & .841 \\
\hline$y_{3}$ & $\begin{array}{r}-.411 \\
(.065 \\
-6.3)\end{array}$ & $\begin{array}{l}.076 \\
(.058 \\
1.3)\end{array}$ & $\begin{array}{r}.516 \\
(.061 \\
8.5)\end{array}$ & $\begin{array}{r}.979 \\
(.075 \\
13.1)\end{array}$ & $\begin{array}{c}1.000^{\mathrm{C}} \\
\ldots \\
\ldots\end{array}$ & $\begin{array}{c}1.146 \\
(.100 \\
11.5)\end{array}$ & .358 & .724 \\
\hline$y_{4}$ & $\begin{array}{r}-1.259 \\
(.060 \\
-21.0)\end{array}$ & $\begin{array}{l}-.530 \\
(.085 \\
-6.2)\end{array}$ & $\begin{array}{c}.278 \\
(.090 \\
3.1)\end{array}$ & $\begin{array}{c}1.220 \\
(.058 \\
21.0)\end{array}$ & $\begin{array}{l}.556 \\
(.149 \\
3.7)\end{array}$ & $\begin{array}{r}.971 \\
(.039 \\
24.9)\end{array}$ & .111 & .161 \\
\hline$y_{5}$ & & & $\begin{array}{l}-1.130 \\
(.063 \\
-17.9)\end{array}$ & $\begin{array}{l}-.153 \\
(.048 \\
-3.2)\end{array}$ & $1.000^{\mathrm{c}}$ & $\begin{array}{l}1.137 \\
(.090 \\
12.6)\end{array}$ & .524 & .407 \\
\hline$y_{6}$ & & & $\begin{array}{l}-.747 \\
(.036 \\
-20.8)\end{array}$ & $\begin{array}{c}.244 \\
(.056 \\
4.4)\end{array}$ & $\begin{array}{r}.997 \\
(.105 \\
9.5)\end{array}$ & $\begin{array}{l}1.417 \\
(.121, \\
11.7)\end{array}$ & .521 & .629 \\
\hline & ${ }^{a}$ Entr & are: & $\begin{array}{l}\text { Estimat } \\
\text { (Standa } \\
\text { Estimat }\end{array}$ & $\begin{array}{l}\text { error, } \\
\text { st. error) }\end{array}$ & & & & \\
\hline
\end{tabular}

and allowing the diagonal $\Delta$ elements to be free for Males (group-variant error variances is frequently observed in multiple-group analysis of continuous indicators). The chisquare for this model was 27.68 with 23 degrees of freedom, indicating a good fit.

We may also compare the above model with the one that in addition postulates sex invariant $B$ and $\Psi$, still allowing for variant $\alpha$ and $\Delta$. The chi-square difference was 29.55 with six degrees of freedom and gives a strong indication of misfit.

In Table 3 we report the estimates for the model with 23 degrees of freedom, allowing for sex differences in $B, \Psi, \alpha$, and $\Delta$. We also give structural parameter estimates in the standardization of unit latent variable construct variances. Males have significantly lower means for both $\eta_{2}$ (which has a negative influence on $\eta_{1}$ ) and $\eta_{3}$ (which has a positive influence on $\eta_{1}$ ). Of particular interest is the estimated sex difference in the $\eta_{1}$ mean. We deduce that there is a significantly smaller value for Males, -.343 with a standard error 
TABLE 3.2

A Structural Equation Model: Estimates for a Model of Partial Sex-Invariance. Structural Parameters ${ }^{a}$

\begin{tabular}{|c|c|c|c|c|}
\hline \multirow[b]{2}{*}{ Parameter } & \multicolumn{2}{|c|}{ Original Values } & \multicolumn{2}{|c|}{ Standardized Values } \\
\hline & Females & Mates & Femates & Males \\
\hline Slope for second construct & $\begin{array}{r}-.687 \\
(.610 \\
-1.1)\end{array}$ & $\begin{array}{l}-.307 \\
(.156 \\
-2.0)\end{array}$ & -.455 & -.390 \\
\hline Slope for third construct & $\begin{array}{l}.366 \\
(.377 \\
1.0)\end{array}$ & $\begin{array}{l}.428 \\
(.097 \\
4.4)\end{array}$ & .293 & .411 \\
\hline Residual variance & $\begin{array}{r}.427 \\
(.117 \\
3.6)\end{array}$ & $\begin{array}{r}.214 \\
(.057 \\
3.8)\end{array}$ & .523 & .626 \\
\hline Variance of second construct & $\begin{array}{l}.358 \\
(.159 \\
2.3)\end{array}$ & $\begin{array}{l}.551 \\
(.298, \\
1.8)\end{array}$ & 1.000 & 1.000 \\
\hline Variance of third construct & $\begin{array}{r}.524 \\
(.082 \\
6.4)\end{array}$ & $\begin{array}{r}.315 \\
(.067 \\
4.7)\end{array}$ & 1.000 & 1.000 \\
\hline $\begin{array}{l}\text { Covariance between second } \\
\text { and third construct }\end{array}$ & $\begin{array}{r}-.298 \\
(.052 \\
-5.7)\end{array}$ & $\begin{array}{l}-.069 \\
(.039 \\
-1.8)\end{array}$ & -.688 & -.166 \\
\hline Intercept & $\begin{array}{l}.000^{b} \\
-- \\
--\end{array}$ & $\begin{array}{l}-.344 \\
(.072 \\
-4.8)\end{array}$ & .000 & -.588 \\
\hline Mean of second construct & $\begin{array}{l}.000^{b} \\
-- \\
--\end{array}$ & $\begin{array}{l}-.162 \\
(.071 \\
-2.3)\end{array}$ & .000 & -.218 \\
\hline Mean of third construct & $\begin{array}{l}.000^{b} \\
-- \\
--\end{array}$ & $\begin{array}{r}-.113 \\
(.057 \\
-2.0)\end{array}$ & .000 & -.201 \\
\hline Deduced mean of first construct & $\begin{array}{l}.000^{b} \\
--\end{array}$ & $\begin{array}{l}-.343 \\
(.065 \\
-5.3)\end{array}$ & .000 & -.380 \\
\hline
\end{tabular}

${ }^{a}$ Entries are: Estimate

(Standard error, Estimate/St. error)

${ }^{b}$ Fixed paraneter

of .065 , corresponding to a $t$ ratio of -5.3 . This may be contrasted with the insignificant sex differences for the $y_{1}, y_{2}$ proportions, reported at the beginning of this example.

For comparison, it is also of interest to give results analogous to those of Table 3 for the case of scoring the observed variables $0,1,2, \ldots$, and applying continuous variable, 
TABLE 4.1

A Structural Equation Mode1: Normal Theory Estimates for

a Model of Partial Sex-Invariance. Measurement Parameters ${ }^{a}$

\begin{tabular}{|c|c|c|c|c|c|c|}
\hline \multirow{3}{*}{$\frac{\text { Variable }}{y_{1}}$} & \multirow{3}{*}{$\begin{array}{c}\text { Intercept } \\
\\
2.404 \\
(.075 \\
32.1)\end{array}$} & \multirow{3}{*}{$\begin{array}{l}\text { Loading } \\
\begin{array}{c}1.000^{b} \\
-- \\
--\end{array}\end{array}$} & \multirow{2}{*}{\multicolumn{2}{|c|}{$\frac{\text { Error Variance }}{\text { Fenlales Males }}$}} & \multicolumn{2}{|c|}{ Reliability } \\
\hline & & & & & Females & MaTes \\
\hline & & & $\begin{array}{r}.276 \\
(.065 \\
4.2)\end{array}$ & $\begin{array}{r}.238 \\
(.065 \\
3.7)\end{array}$ & .700 & .730 \\
\hline$y_{2}$ & $\begin{array}{c}1.754 \\
(.029 \\
60.5)\end{array}$ & $\begin{array}{c}.580 \\
(.054 \\
10.7)\end{array}$ & $\begin{array}{r}.108 \\
(.023 \\
4.7)\end{array}$ & $\begin{array}{r}.126 \\
(.023 \\
5.5)\end{array}$ & .668 & .632 \\
\hline$y_{3}$ & $\begin{array}{r}1.574 \\
(.075, \\
21.0)\end{array}$ & $\begin{array}{c}1.000^{b} \\
\cdots \\
\cdots\end{array}$ & $\begin{array}{r}1.269 \\
(.211 \\
6.0)\end{array}$ & $\begin{array}{r}.976 \\
(.201 \\
4.9)\end{array}$ & .413 & .456 \\
\hline $\mathrm{y}_{4}$ & $\begin{array}{l}2.070 \\
(.054 \\
38.3)\end{array}$ & $\begin{array}{r}.591 \\
(.107 \\
5.5)\end{array}$ & $\begin{array}{r}.998 \\
(.096 \\
10.4)\end{array}$ & $\begin{array}{r}1.120 \\
(.115 \\
9.7)\end{array}$ & .238 & .203 \\
\hline$y_{5}$ & $\begin{array}{c}1.445 \\
(.034 \\
42.5)\end{array}$ & $\begin{array}{c}1.000^{b} \\
--\end{array}$ & $\begin{array}{r}.320 \\
(.039 \\
8.2)\end{array}$ & $\begin{array}{r}.328 \\
(.040 \\
8.2)\end{array}$ & .359 & .353 \\
\hline$y_{6}$ & $\begin{array}{r}1.180 \\
(.039 \\
30.3)\end{array}$ & $\begin{array}{l}1.156 \\
(.179 \\
6.5)\end{array}$ & $\begin{array}{c}.352 \\
(.047 \\
7.5)\end{array}$ & $\begin{array}{r}.260 \\
(.046 \\
5.7)\end{array}$ & .405 & .479 \\
\hline & s are: & $\begin{array}{l}\text { nate } \\
\text { ndard } \\
\text { nate/s }\end{array}$ & or) & & & \\
\hline
\end{tabular}

normal theory methodology. The GLS estimator assuming group-invariant $v$ and $\Lambda$ ( $\tau$ is not involved) resulted in a chi-square of 16.59 with 18 degrees of freedom. The estimates are given in Table 4. Due to differences in metrics, only standardized values (including $t$-ratios and reliabilities) are comparable across Table 4 and Table 3 . Due to the distortions in associations referred to above, the normal theory methodology generally gives a somewhat different and a more "pessimistic" picture than the categorical variable methodology. Much of the distortion is absorbed by the measurement parameters, but some permeates to the structural parameters. For instance, $R^{2}$ for $\eta_{1}$ is $47.7 \%$ for Females in Table 3 and $23.6 \%$ in Table 4. For Males the corresponding numbers are 37.4 and 31.3. Also, the $t$-ratio for the sex-difference in the $\eta_{1}$ mean is almost five times larger in the categorical variable methodology.

\subsection{A Longitudinal Model}

The second data set illustrates Case B of the general model. The author is obliged to Paul Duncan-Jones at the Australian National University, Canberra, for providing the 
TABLE 4.2

A Structural Equation Model: Normal Theory Estimates for a Model of Partial Sex-Invariance. Structural Parameters ${ }^{\text {a }}$

\begin{tabular}{|c|c|c|c|c|}
\hline \multirow{2}{*}{ Parameter } & \multicolumn{2}{|c|}{ Original Values } & \multicolumn{2}{|c|}{ Standardized Values } \\
\hline & Females & Males & Femaic & Mates \\
\hline Slope for second construct & $\begin{array}{r}-.211 \\
(.112 \\
-1.9)\end{array}$ & $\begin{array}{r}-.341 \\
(.100 \\
-3.4)\end{array}$ & -.248 & -.384 \\
\hline Slope for third construct & $\begin{array}{r}.563 \\
(.238 \\
2.4)\end{array}$ & $\begin{array}{c}.700 \\
(.181 \\
3.9)\end{array}$ & .297 & .352 \\
\hline Residual variance & $\begin{array}{r}.493 \\
(.073 \\
6.8)\end{array}$ & $\begin{array}{r}.442 \\
(.077 \\
5.7)\end{array}$ & .764 & .687 \\
\hline Variance of second construct & $\begin{array}{r}.893 \\
(.220 \\
4.1)\end{array}$ & $\begin{array}{r}.817 \\
(.205 \\
4.0)\end{array}$ & 1.000 & 1.000 \\
\hline Variance of third construct & $\begin{array}{r}.179 \\
(.039 \\
4.6)\end{array}$ & $\begin{array}{r}.163 \\
(.037 \\
4.4)\end{array}$ & 1.000 & 1.000 \\
\hline $\begin{array}{c}\text { Covariance between second } \\
\text { and third construct }\end{array}$ & $\begin{array}{r}-2.34 \\
(.048 \\
-4.9)\end{array}$ & $\begin{array}{r}-.056 \\
(.039 \\
-1.4)\end{array}$ & -.448 & -.153 \\
\hline Intercept & $\begin{array}{l}.000^{b} \\
\cdots\end{array}$ & $\begin{array}{r}-.131 \\
(.076 \\
-1.7)\end{array}$ & .000 & -.163 \\
\hline Mean of second construct & $\begin{array}{l}.000^{b} \\
-- \\
--\end{array}$ & $\begin{array}{r}-.273 \\
(.101 \\
-2.7)\end{array}$ & .000 & -.302 \\
\hline Mean of third construct & $\begin{array}{l}.000^{b} \\
\ldots \\
\ldots\end{array}$ & $\begin{array}{r}-.055 \\
(.044 \\
-1.3)\end{array}$ & .000 & -.130 \\
\hline Deduced mean of first construct & $\begin{array}{l}.000^{b} \\
--\end{array}$ & $\begin{array}{r}-.076 \\
(.070 \\
-1.1)\end{array}$ & .000 & -.095 \\
\hline
\end{tabular}

${ }^{a}$ Entries are: Estimate

(Standard error, Estimate/St. error)

$b_{\text {Fixed parameter }}$

data. A random sample of Canberra electors were interviewed four times with four-month intervals in 1977 and 1978. The data are fully described by Henderson, Byrne, and Duncan-Jones (1981). For our illustrations we will analyze data from the first and last occasion, for 231 individuals with complete data. At each occasion we consider three dichotomous items intended to measure "neurotic illness," 
TABLE 5

A Longitudinal Model: Descriptive Statistics

for the Independent Variables

\begin{tabular}{|c|c|c|c|c|c|}
\hline & N & LI & L2 & L3 & $L 4$ \\
\hline \multicolumn{6}{|c|}{ Correlations } \\
\hline$N$ & 1.0000 & & & & \\
\hline LI & 0.2162 & 1.0000 & & & \\
\hline L2 & 0.1595 & 0.5377 & 1.0000 & & \\
\hline L3 & 0.1807 & 0.4967 & 0.4937 & 1.0000 & \\
\hline$\llcorner 4$ & 0.2059 & 0.5270 & 0.4886 & 0.5144 & 1.0000 \\
\hline \multicolumn{6}{|c|}{ Variances } \\
\hline & 20.6573 & 6.5372 & 5.8932 & 4.8975 & 5.2707 \\
\hline \multicolumn{6}{|c|}{ Means } \\
\hline & 9.3074 & 3.8615 & 3.1732 & 2.5758 & 2.4199 \\
\hline
\end{tabular}

"In the last month have you suffered from any of the following?"

Anxiety

Depression

Irritability

The response Yes was denoted by $y=1$ and No by $y=0$. Below the abbreviations $A, D, I$ will be used for these three indicators. It was hypothesized that at each time point (one and four) these three items may be viewed as indicators of latent variable constructs $\eta_{1}$ and $\eta_{4}$, "current level of neurotic illness." The latent variable constructs are related to a set of observed continuous variables: the $N$ scale from the Eysenck Personality Inventory $(N)$ and number of "life events" occurring to the respondent in the four months prior to each interview (L1, L2, L3, L4). The variable $N$ is intended to measure long-term liability to neurosis and is taken here as the average score from occasions two and four. Descriptive statistics for the background variables are given in Table 5, and the model is given in path diagram form in Figure 2.

Since the same $y$-items have been administered at the two occasions we may hypothesize time-invariance of the thresholds and loadings. We may allow for different intercepts at the two time points and also allow the variances of the measurement errors of $\varepsilon$ to vary over time by specifying $\Delta$ as diag $(\Delta)=\left(\begin{array}{lllllll}1 & 1 & 1 & \delta_{1} & \delta_{2} & \delta_{3}\end{array}\right)$, where the unit elements are fixed.

The above model is fitted into the general framework by using part 1,2 , and 3 . Here, $\sigma_{1}, \sigma_{2}$, and $\sigma_{3}$ have $6,30,15$ elements, respectively. A chi-square value of 32.03 with 32 


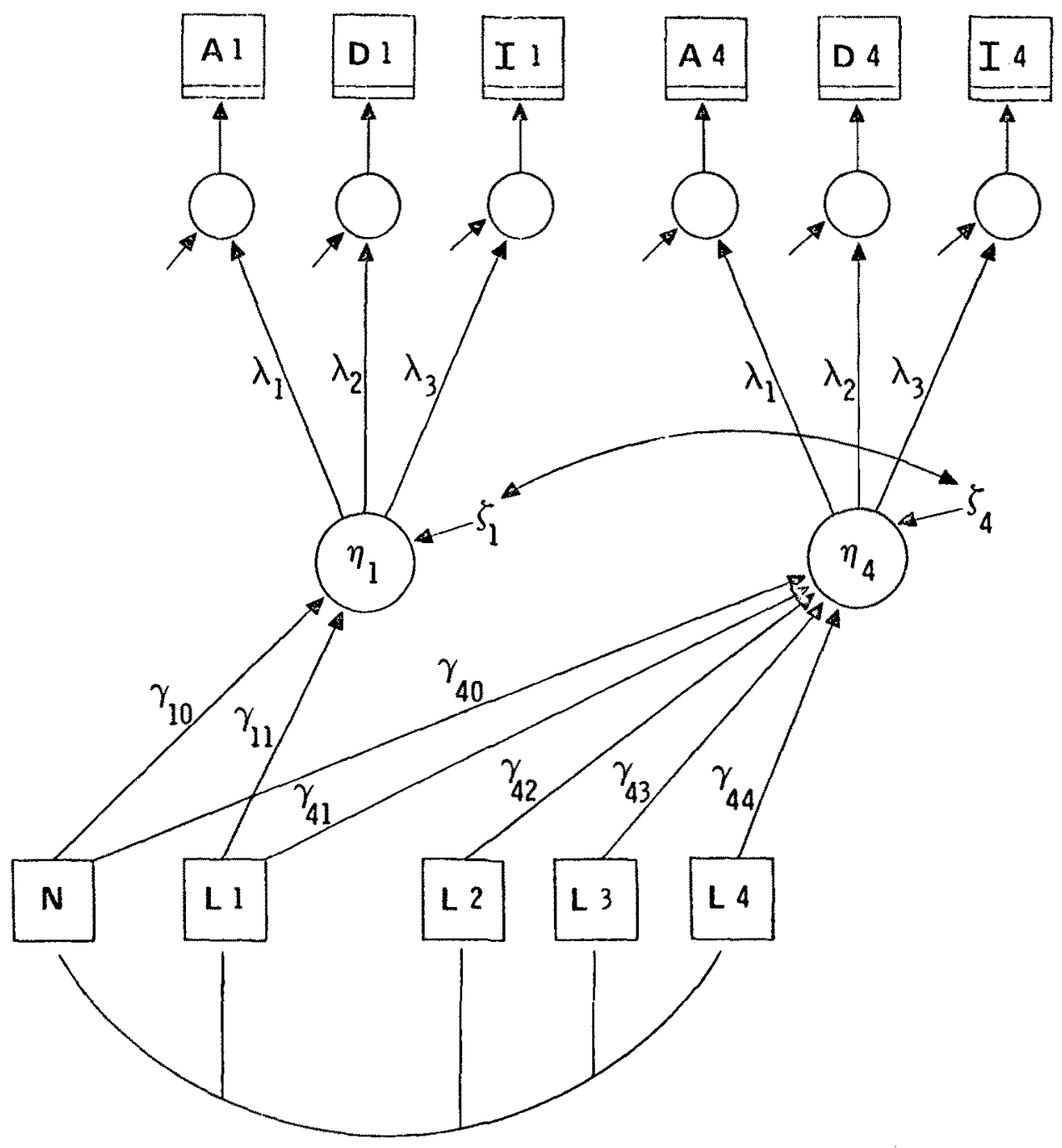

FIGURE 2.

A Longitudinal Model.

degrees of freedom is obtained with the GLS estimator. Hence the notion that we are tapping the same latent variable construct at the two time points cannot be rejected. Had a significant value been obtained, the three-part model structure makes it convenient to separately test for fit the relations between the $y$ 's and the $x$ 's and between the $y$ 's.

The parameter estimates are given in Table 6 . From Table 6 we note a significantly larger intercept in the structural relation for the last occasion as compared to the first. Using the sample means of $N, L_{1}, L_{2}, L_{3}$, and $L_{4}$ we find estimated $\eta_{1}$ and $\eta_{4}$ means of 1.236 and 1.356 , respectively. We may also note the difference in regression slopes for $N$. A chi-square test of slope equality with one degree of freedom obtains a significant value of 11.43 . This could indicate that the presumed stability over time of the liability to neurosis does not hold true as measured by $N$.

We may also further constrain the model by specifying time-invariant measurement error variances. This means that we would have time-invariant probit regressions for each 
TABLE 6

A Longitudinal Model: Estimated Parameters ${ }^{a}$

\begin{tabular}{|c|c|c|c|c|c|c|}
\hline Item & \multicolumn{2}{|l|}{ Thresholds } & \multicolumn{2}{|l|}{ Loadings } & \multicolumn{2}{|c|}{$\begin{array}{l}\text { Time-point } 4 \\
\text { Scale Factors }\end{array}$} \\
\hline$A$ & $\begin{array}{l}1.915 \\
(.220)\end{array}$ & & $1.000^{b}$ & & $\begin{array}{l}2.030 \\
(.974)\end{array}$ & \\
\hline D & $\begin{array}{l}2.451 \\
(.299)\end{array}$ & & $\begin{array}{l}1.344 \\
(.170)\end{array}$ & & $\begin{array}{l}1.875 \\
(.949)\end{array}$ & \\
\hline I & $\begin{array}{l}1.161 \\
(.180)\end{array}$ & & $\begin{array}{l}0.721 \\
(.128)\end{array}$ & & $\begin{array}{c}3.358 \\
(1.975)\end{array}$ & \\
\hline \multicolumn{7}{|c|}{ Structural Regression Coefficients } \\
\hline & Intercept & $N$ & $\mathrm{~L}_{1}$ & $L_{2}$ & $L_{3}$ & $\mathrm{~L}_{4}$ \\
\hline Time-point 1 & $.0^{b}$ & $\begin{array}{l}.100 \\
(.016)\end{array}$ & $\begin{array}{l}.079 \\
(.027)\end{array}$ & $.0^{b}$ & $.0^{b}$ & $0^{\mathrm{b}}$ \\
\hline Time-point 4 & $\begin{array}{l}.975 \\
(.456)\end{array}$ & $\begin{array}{l}.023 \\
(.013)\end{array}$ & $\begin{array}{l}.031 \\
(.020)\end{array}$ & $\begin{array}{l}-.032 \\
(.020)\end{array}$ & $\begin{array}{l}-.011 \\
(.010)\end{array}$ & $\begin{array}{l}.050 \\
(.029)\end{array}$ \\
\hline \multicolumn{7}{|c|}{ Residual covariance matrix } \\
\hline Time-point 1 & $\begin{array}{l}.486 \\
(.087)\end{array}$ & & & & & \\
\hline Time-point 4 & $\begin{array}{l}.159 \\
(.082)\end{array}$ & $\begin{array}{l}.102 \\
(.102)\end{array}$ & & & & \\
\hline
\end{tabular}

\footnotetext{
${ }^{a}$ Standard errors are given in parentheses.

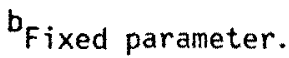

of the $A, D, I$ items on the respective $\eta$; see also Muthén and Christoffersson $(1981, \mathrm{p}$. 411). Still allowing for time-varying residual variances, this specification is consistent with the restriction $\delta_{1}=\delta_{2}=\delta_{3}$. However, this hypothesis is rejected with a chi-square of 8.06 on two degrees of freedom.

\section{Conclusion}

In the preceding sections developments have been presented for appropriately dealing with ordered categorical indicators in structural equation models. What are the limitations?

First of all, normality of underlying latent variables was specified. In a Pearsonian spirit, the categorical variables were viewed as manifestations of continuous normal variables. The present author does not believe that underlying normality is always the most appropriate specification. This modeling needs to be confronted with data, e.g. as was done in Table 2. It is unknown how sensitive results are to deviations from this state of affairs. The normality specification is perhaps less strict in Case B models, where the 
latent response variable distribution is to some extent generated by the $x$ distribution and the normality specification is on the residuals.

The GLS (as opposed to an unweighted least squares) estimator requires the creation of a weight matrix which grows very rapidly with the number of $y$-variables. This limits its practical use to about $15-20$ variables, i.e. small-sized problems or the scrutinizing of marginal parts of models. No doubt the appropriate creation of the weight matrix requires large samples. Further research needs to show what the requirements actually are (e.g., in terms of bivariate frequencies for polychorics).

Although data are often observed in the form discussed here, some researchers may find the proposed modeling too complex. People in the scaling tradition may prefer some optimal scaling approach, while LISREL users may choose to ignore the scale problem. The former approach would seem to give a less powerful analysis. As we have seen, the latter way out may be undesirable, although often it may not make that much of a difference for structural parameters. However, to quote Cox $(1970$, p. 18) in discussing logit versus ordinary regression: "the use of a model, the nature of whose limitations can be foreseen, is not wise, except for very limited purposes." Our approach is computationally heavy, but it gives an interesting possibility for a rather detailed analysis. The GLS estimator provides a general approach for analyzing any kind of statistics for which the three-part structure is relevant. What is needed is to find the appropriate weight matrix.

\section{REFERENCE NOTES}

1. Gruveaus, G. T., \& Jöreskog, K. G. (1970). A computer program for minimizing a function of several variables. Research Bulletin 70-14. Princeton, N.J.: Educational Testing Service.

2. Jöreskog, K. G., \& Sörbom, D. (1981). LISREL V. Analysis of linear structural relationships by maximum likelihood and least squares methods. Research Report 81-8, Department of Statistics, University of Uppsala.

\section{REFERENCES}

Browne, M. W. (1974). Generalized least squares estimates in the analysis of covariance structures. South African Statistical Journal, 8, 1-24. (Reprinted in D. J. Aigner, \& A. S. Goldberger (Eds.), (1977), Latent variables in socio-economic models. Amsterdam: North-Holland.)

Cox, D. R. (1970). The analysis of binary data. London: Methuen.

Henderson, A. S., Byrne, D. G., \& Duncan-Jones, P. (1981). Neurosis and the social environment. Sidney: Academic Press.

Jöreskog, K. G. (1973). A general method for estimating a linear structural equation system. In A. S. Goldberger and $O$. D. Duncan (Eds.), Structural equation models in the social sciences. New York: Seminar Press, $85-112$.

Jöreskog, K. G. (1977). Structural equation models in the social sciences: Specification, estimation and testing. In P. R. Krishnaiah (Ed.), Applications of statistics. Amsterdam: North-Holland.

Muthén, B. (1978). Contributions to factor analysis of dichotomous variables. Psychometrika, 43, 551-560.

Muthén, B. (1979). A structural probit model with latent variables. Journal of the American Statistical Association, 74, 807-811.

Muthén, B. (1983). Latent variable structural equation modeling with categorical data. Journal of Econometrics, $22,43-65$.

Muthén, B., \& Christoffersson, A. (1981). Simultaneous factor analysis of dichotomous variables in several groups. Psychometrika, 46, 407-419.

Olsson, U. (1979). Maximum likelihood estimation of the polychoric correlation coefficient. Psychometrika, 44, 443-460. (a)

Olsson, U. (1979). On the robustness of factor analysis against crude classification of the observations. Multivariate Behavioral Research, 14, 485-500. (b)

Olsson, U., Drasgow, F., \& Dorans, N. J. (1982). The polyserial correlation coefficient. Psychometrika, 47, $337-347$.

Sörbom, D. (1982). Structural equation models with structured means. In K. G. Jöreskog \& H. Wold (Eds.), Systems under indirect observation: Causality, structure, prediction. Amsterdam: North-Holland Publishing Company. 